\title{
A Compact Tritium AMS System
}

M.L. Roberts, R.W. Hamm, K.H. Dingley, M.L. Chiarappa and A.H. Love

This article was submitted to

$8^{\text {th }}$ International Conference on Accelerator Mass Spectrometry Vienna, Austria

September 6-10, 1999

\section{September 23, 1999}

U.S. Department of Energy

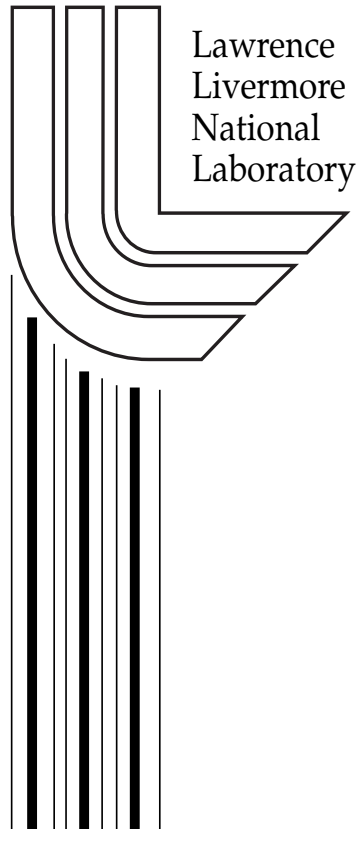




\section{DISCLAIMER}

This document was prepared as an account of work sponsored by an agency of the United States Government. Neither the United States Government nor the University of California nor any of their employees, makes any warranty, express or implied, or assumes any legal liability or responsibility for the accuracy, completeness, or usefulness of any information, apparatus, product, or process disclosed, or represents that its use would not infringe privately owned rights. Reference herein to any specific commercial product, process, or service by trade name, trademark, manufacturer, or otherwise, does not necessarily constitute or imply its endorsement, recommendation, or favoring by the United States Government or the University of California. The views and opinions of authors expressed herein do not necessarily state or reflect those of the United States Government or the University of California, and shall not be used for advertising or product endorsement purposes.

This is a preprint of a paper intended for publication in a journal or proceedings. Since changes may be made before publication, this preprint is made available with the understanding that it will not be cited or reproduced without the permission of the author.

This report has been reproduced directly from the best available copy.

Available to DOE and DOE contractors from the

Office of Scientific and Technical Information

P.O. Box 62, Oak Ridge, TN 37831

Prices available from (423) 576-8401

http://apollo.osti.gov/bridge/

Available to the public from the National Technical Information Service

U.S. Department of Commerce 5285 Port Royal Rd., Springfield, VA 22161 http://www.ntis.gov/

OR

Lawrence Livermore National Laboratory Technical Information Department's Digital Library http://www.llnl.gov/tid/Library.html 


\section{A Compact Tritium AMS System}

M.L. Roberts ${ }^{[a]}$, R.W. Hamm ${ }^{[b]}$, K.H. Dingley ${ }^{[a]}$, M.L. Chiarappa ${ }^{[a]}$, and A.H. Love ${ }^{[c]}$

${ }^{[a]}$ Lawrence, Livermore National Laboratory, Livermore, CA 94551 USA

${ }^{[b]}$ AccSys Technology, Inc., Pleasanton, CA 94566 USA

${ }^{[c]}$ University of California, Berkeley, CA 94720 USA

This paper was prepared for submittal to the

8th International Conference on Accelerator Mass Spectrometry

Vienna, Austria

September 6-10, 1999 


\title{
A Compact Tritium AMS System
}

\author{
M.L. Roberts ${ }^{[a]}$, R.W. Hamm ${ }^{[b]}$, K.H. Dingley ${ }^{[a]}$, M.L. Chiarappa ${ }^{[a]}$, and A.H. Love ${ }^{[c]}$ \\ ${ }^{[a]}$ Lawrence, Livermore National Laboratory, Livermore, CA 94551 USA $^{*}$ \\ ${ }^{[b]}$ AccSys Technology, Inc., Pleasanton, CA 94566 USA $^{* *}$ \\ ${ }^{[c]}$ University of California, Berkeley, CA 94720 USA
}

\begin{abstract}
Tritium $\left({ }^{3} \mathrm{H}\right)$ is a radioisotope that is extensively utilized in biological and environmental research. For biological research, ${ }^{3} \mathrm{H}$ is generally quantified by liquid scintillation counting requiring gram-sized samples and counting times of several hours. For environmental research, ${ }^{3} \mathrm{H}$ is usually quantified by ${ }^{3} \mathrm{He}$ in-growth which requires gram-sized samples and in-growth times of several months. In contrast, provisional studies at LLNL's Center for Accelerator Mass Spectrometry have demonstrated that Accelerator Mass Spectrometry (AMS) can be used to quantify ${ }^{3} \mathrm{H}$ in milligram-sized biological samples with a 100 to 1000-fold improvement in detection limits when compared to scintillation counting. This increased sensitivity is expected to have great impact in the biological and environmental research community. However in order to make the ${ }^{3} \mathrm{H}$ AMS technique more broadly accessible, smaller, simpler, and less expensive AMS instrumentation must be developed. To meet this need, a compact, relatively low cost prototype ${ }^{3} \mathrm{H}$ AMS system has been designed and built based on a LLNL ion source/sample changer and an AccSys Technology, Inc. Radio Frequency Quadrupole (RFQ) linac. With the prototype system, ${ }^{3} \mathrm{H} /{ }^{1} \mathrm{H}$ ratios ranging from $1 \times 10^{-10}$ to $1 \times 10^{-13}$ have be measured from milligram sized samples. With improvements in system operation and sample preparation methodology, the sensitivity limit of the system is expected to increase to approximately $1 \times 10^{-15}$.
\end{abstract}

*This work performed under the auspices of the U.S. Department of Energy at the Lawrence Livermore National Laboratory under contract W-7405-Eng-48.

\footnotetext{
**This work was supported by Grant Number 2R44CA69960-02 from the National Cancer Institute. The contents of this paper are solely the responsibility of the authors and do not necessarily represent the official views of the National Cancer Institute.
} 


\section{Background}

The initial motivation to develop ${ }^{3} \mathrm{H}$ AMS came from the results of applying the ${ }^{14} \mathrm{C}$ AMS technique to biomedical and environmental tracer research. Lawrence Livermore National Laboratory (LLNL) pioneered the use of ${ }^{14} \mathrm{C}$ AMS in the biological sciences ${ }^{[1]}$ and has shown that the application of ${ }^{14} \mathrm{C}$ AMS can provide an increase of $10^{3}$ in detection sensitivity over liquid scintillation counting, allowing a $10^{3}$ reduction in sample size or a $10^{3}$ decrease in delivered radio-isotope dose. Consequently, it has been possible to trace environmentally relevant doses of carcinogens or nutrients in laboratory animals and humans with very high sensitivity ${ }^{[2-4]}$.

Development of a bio- ${ }^{3} \mathrm{H}$ AMS capability is also expected to have great impact in the biological research community for two significant reasons. First, ${ }^{3} \mathrm{H}$ is the most widely used radioisotope in biological research, with the number of commercially available ${ }^{3} \mathrm{H}$-labeled compounds far exceeding the number of commercially available ${ }^{14} \mathrm{C}$-labeled compounds. Therefore, a ${ }^{3} \mathrm{H}$ AMS measurement capability will permit experiments using compounds that are either prohibitively expensive or simply unavailable in ${ }^{14} \mathrm{C}$-labeled form. Second, a ${ }^{3} \mathrm{H}$ AMS capability, when used in conjunction with ${ }^{14} \mathrm{C}$ AMS, would allow low-level double-labeling experiments. Such dual labeling experiments permit the study of the interaction of two independent but co-administered compounds, a situation more relevant to human exposures.

While preliminary ${ }^{3} \mathrm{H}$ AMS work has shown great promise ${ }^{[5]}$, it has become clear that before ${ }^{3} \mathrm{H}$ AMS can be used routinely and successfully in the biological and environmental sciences, smaller and simpler AMS instrumentation needs to be developed which would fall within the financial, resource, and space limitations of a typical university or regional medical research center. Consequently, LLNL has collaborated with AccSys Technology, Inc. of Pleasanton, California in a National Institutes of Health/National Cancer Institute Small Business Innovation Research (SBIR) project to build and demonstrate a prototype compact ${ }^{3} \mathrm{H}$ AMS system.

\section{System Description}

A picture of the prototype ${ }^{3} \mathrm{H}$ AMS system is shown in Figure 1 . The ${ }^{3} \mathrm{H}$ AMS system (covered under LLNL/U.S. Patent Number 5,189,302) is based on a LLNL ion source/sample changer ${ }^{[6,7]}$ and an AccSys Technology, Inc. RFQ linac (covered under U.S. Patent Number 5,315,120). The LLNL ion source/sample changer design was chosen because of its high output currents (over $30 \mu \mathrm{A}$ of $\mathrm{H}^{-}$is typical) and its large capacity sample changer (64 samples). An RFQ was chosen because of its inherent compact size (in this case $<1.5 \mathrm{~m}$ ), its relative simplicity of operation, and its ability to simultaneously accelerate all three hydrogen isotopic species to energies sufficient for each species to be separately but simultaneously measured using a simple magnetic spectrometer. Particles with masses above ${ }^{3} \mathrm{H}$ are not accelerated by the $R F Q$, a feature that greatly reduced the complexity of the input beam transport line because no mass analysis is required. A description of how an RFQ works and a brief description of the history of RFQ's is presented in Appendix A: Description and Brief History of RFQ's. 


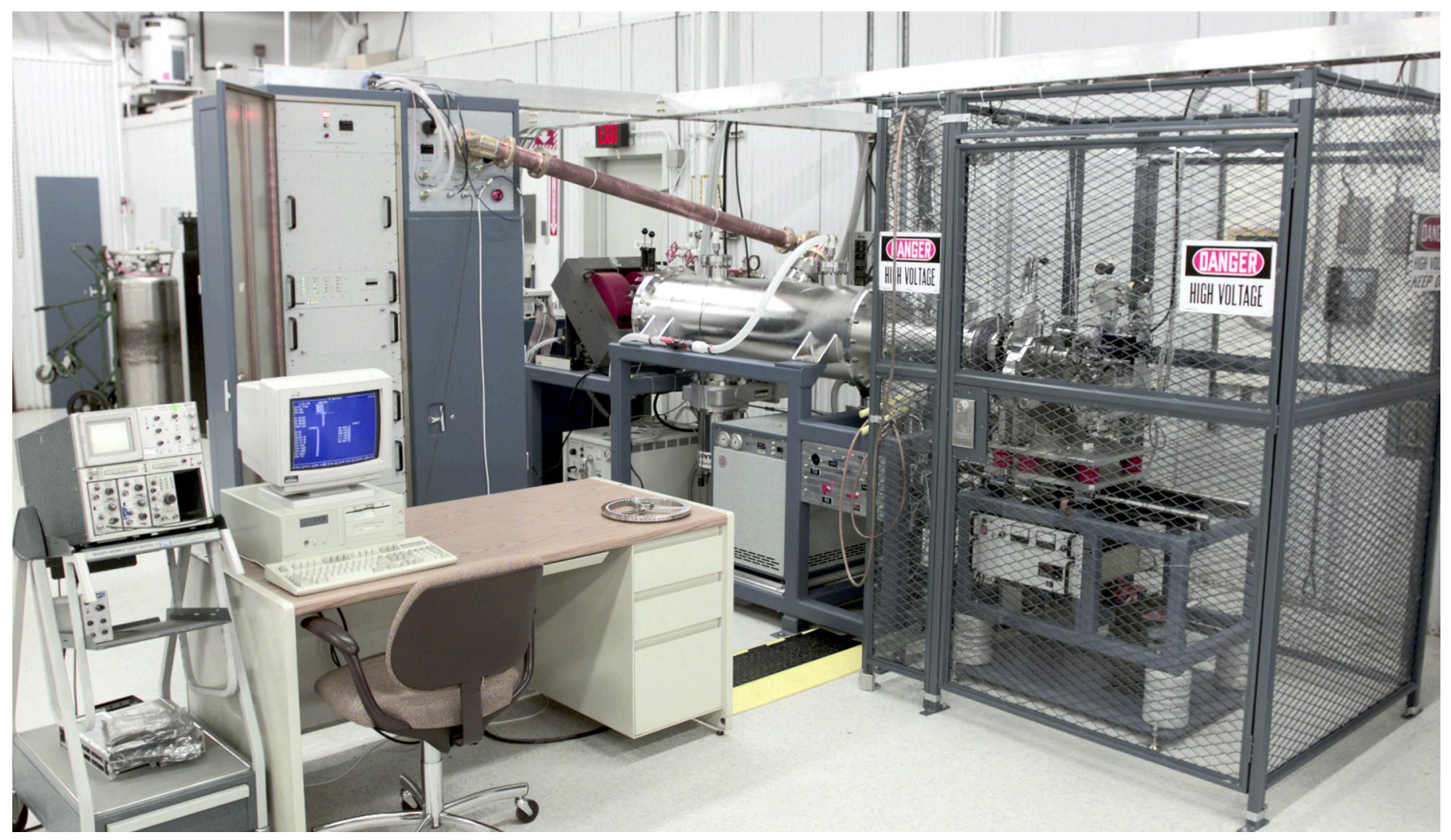

Figure 1. The prototype ${ }^{3} \mathrm{H}$ AMS system. The LLNL ion source/sample changer is seen on the right while the AccSys Technology, Inc. RFQ is in the center. The RFQ is $1.38 \mathrm{~m}$ long and simultaneously accelerates ${ }^{3} \mathrm{H}$ ions to $1.5 \mathrm{MeV}$ and ${ }^{1} \mathrm{H}$ ions to 0.5 $\mathrm{MeV}$. Final mass analysis is performed using a small magnetic spectrometer.

Prior to construction of the prototype ${ }^{3} \mathrm{H}$ AMS system, the beam dynamics code PARMTEC ${ }^{[8]}$ was run for the system. Figure 2 shows the calculated output energy spectrum and calculated beam transmissions for all three hydrogen species. The beam dynamics code also demonstrated that no ion species above mass 3 would be accelerated through the RFQ, even if they fell within the RFQ's input phase space acceptance. These heavier ion species could, however, 'drift' through the RFQ while retaining an energy essentially equal to that of the acceleration voltage of the ion source. In practice, these heavy, but low energy, ions are stopped in the stripper foil. The output beam phase space of the accelerated hydrogen ions was used in beam optics calculations to design a simple mass spectrometer for the high energy end of the system. 


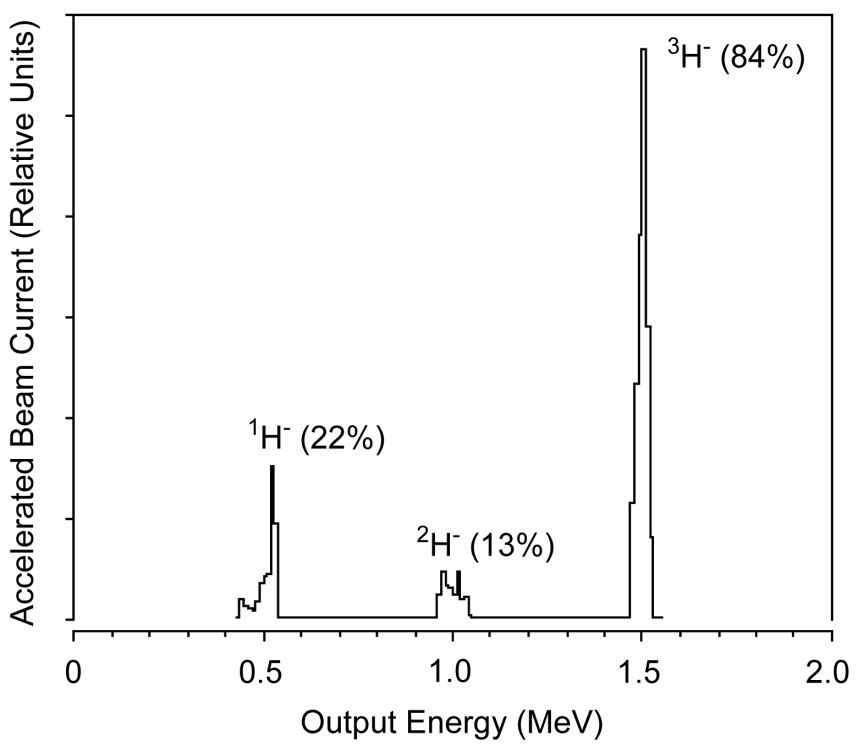

Figure 2. Calculated output energy spectrum for all three hydrogen species for the ${ }^{3} \mathrm{H}$ AMS system. The percents are calculated beam transmissions.

The RFQ parameters for the prototype ${ }^{3} \mathrm{H}$ AMS system are given in Table I. The RFQ is driven by a 1-5/8 inch coaxial drive loop at its midpoint and is housed in a stainless steel vacuum chamber that is supported on a box-beam frame that also supports the input ion source beam line and the high energy spectrometer. Because the RFQ will only accelerate hydrogen species, no complicated transport elements are required to pre-analyze the input beam and a simple electrostatic lens can be used to focus the beam extracted from the ion source into the RFQ. Immediately downstream from the RFQ are two small permanent magnet quadrupole lenses. These lenses are used to focus all of the hydrogen ions from the accelerator through a stripper foil. The stripper foil is needed in order to dissociate the molecular interferences (such as $\mathrm{HD}$ or $\mathrm{H}_{3}$ ) prior to the ions entering the magnetic field of the high energy mass spectrometer. The stripper foil also stops any low energy heavy ions that drifted through the RFQ. After stripping, the positive hydrogen ions enter the mass spectrometer consisting of a single dipole magnet. The vacuum chamber within the dipole magnet has beam ports at $72.6^{\circ}$ port for the ${ }^{1} \mathrm{H}$ beam faraday cup, at $41.4^{\circ}$ for detection of ${ }^{2} \mathrm{H}$ ions, and at $27.3^{\circ}$ for the ${ }^{3} \mathrm{H}$ detector. The ${ }^{3} \mathrm{H}$ detector is a standard silicon charged particle detector mounted by a BNC vacuum-feedthrough. Two 2.5 micron thick Havar foils were placed in front of the charged particle detector to stop multiply scattered low energy ${ }^{1} \mathrm{H}$ ions and differentially lower the energy of any HD molecular interferences that survive the first stripper foil.

Table I. ${ }^{3} \mathrm{H}$ AMS RFQ Design

\begin{tabular}{|l|c|l|}
\hline Operating frequency & 425 & $\mathrm{MHz}$ \\
\hline Injector voltage & 50. & $\mathrm{kV}$ \\
\hline Output ion energy(all species) & 0.50 & $\mathrm{MeV} / \mathrm{amu}$ \\
\hline Length & 1.38 & $\mathrm{~m}$ \\
\hline Acceptance (normalized) & 0.70 & $\pi \mathrm{mm}-\mathrm{mrad}$ \\
\hline Peak RF power & 120 & $\mathrm{~kW}$ \\
\hline Mass 3 transmission & $>80$ & $\%$ \\
\hline Simultaneous mass 1 transmission & $\sim 22$ & $\%$ \\
\hline
\end{tabular}




\section{Results and Discussion}

In order to characterize the prototype ${ }^{3} \mathrm{H}$ AMS system, ${ }^{3} \mathrm{H} /{ }^{1} \mathrm{H}$ ratios were measured from several water standards. Typical ion energy versus count spectra are shown in Figure 3 for two water standards and one blank water standard. As determined by liquid scintillation counting, the W1 standard has a ${ }^{3} \mathrm{H} /{ }^{1} \mathrm{H}$ ratio of $9.1( \pm 0.1) \times 10^{-11}$, the W2 standard has a ${ }^{3} \mathrm{H} /{ }^{1} \mathrm{H}$ ratio of $9.4( \pm 0.1)$ $\mathrm{x} 10^{-12}$, and the blank standard has ${ }^{3} \mathrm{H} /{ }^{1} \mathrm{H}$ ratio of less than $1 \times 10^{-15}$. For the AMS measurements, $2 \mu \mathrm{l}$ of the water standards were converted to titanium hydride using a method described by Roberts et al. ${ }^{[9]}$ All standards had approximately the same ${ }^{1} \mathrm{H}$ ion currents and were acquired for approximately the same acquisition time of $100 \mathrm{~s}$. For the W1 standard the ${ }^{3} \mathrm{H}$ count rate was approximately 40 counts per second.
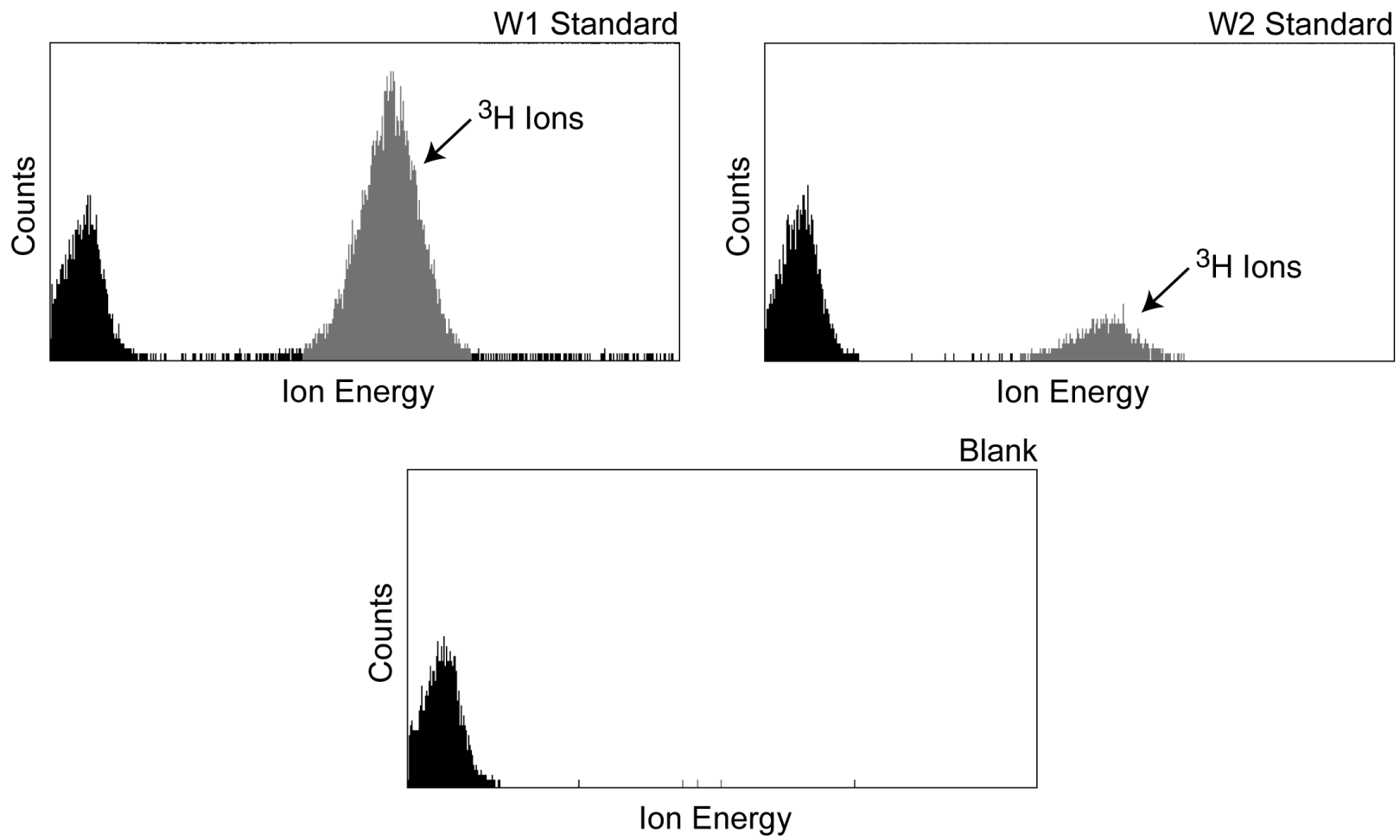

Figure 3. Ion energy versus counts spectra for three water standards with differing ${ }^{3} \mathrm{H} /{ }^{1} \mathrm{H}$ ratios. The mean energy of the ${ }^{3} \mathrm{H}$ ions after passing through the two 2.5 micron thick Havar foils is approximately $0.5 \mathrm{MeV}$. The peak on the left side of the spectra is electronic noise in the detector system.

Figure 4 shows measured ${ }^{3} \mathrm{H} /{ }^{1} \mathrm{H}$ AMS ratios as compared to ${ }^{3} \mathrm{H} /{ }^{1} \mathrm{H}$ ratios determined from liquid scintillation counting from four different water standards. Each data point represents the average of between 32 and 12 separate measurements. The correlation between measured and expected values is good $(\mathrm{r}=0.999)$. Repeat measurements from any single sample gives reproducible results generally to within the limit of counting statistics. For the W1 standard, the standard deviation was $4.1 \%$. For the $\mathrm{W} 4$ standard, the standard deviation was $28 \%$. The current limit of sensitivity of the system is less than $2 \times 10^{-14}$ and compares favorably with the sensitivity of the larger LLNL AMS system ${ }^{[9]}$. As we continue to optimize and make improvements in the sample preparation methodology and system operation, it is expected that the agreement between 
expected and measured ratios will increase and the limit of detection will be lowed to approximately $1 \times 10^{-15}$.

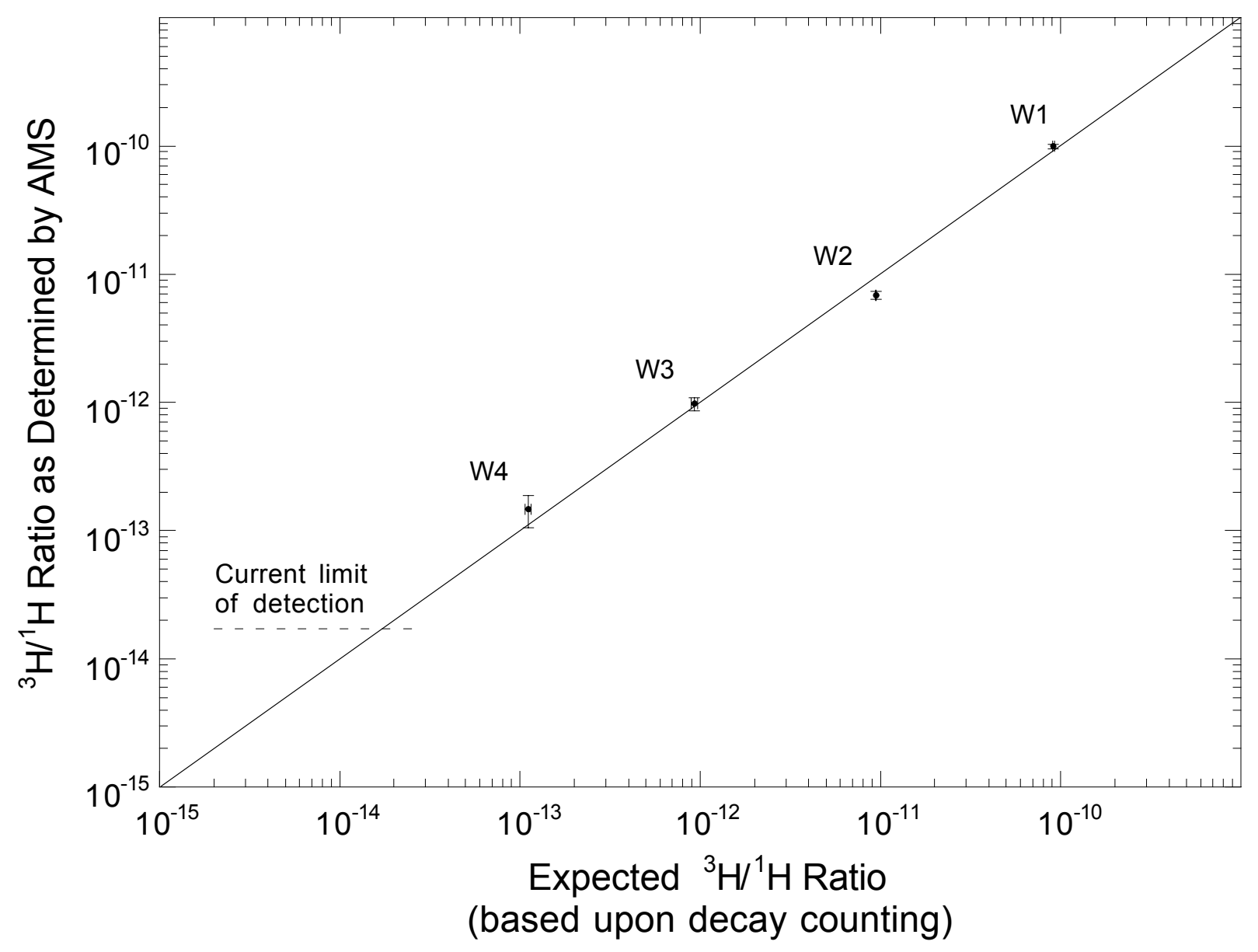

Figure 4. Measured ${ }^{3} \mathrm{H} /{ }^{1} \mathrm{H}$ ratios from various water standards as compared to ratios determined from liquid scintillation counting.

\section{Conclusion}

A prototype ${ }^{3} \mathrm{H}$ AMS system has been designed and built through a National Institutes of Health Small Business Innovation Research grant. Using the prototype ${ }^{3} \mathrm{H}$ AMS system, ${ }^{3} \mathrm{H} /{ }^{1} \mathrm{H}$ ratios have been measured from various water standards and found to agree with ${ }^{3} \mathrm{H} /{ }^{1} \mathrm{H}$ ratios determined from liquid scintillation counting. With the prototype system, ${ }^{3} \mathrm{H} /{ }^{1} \mathrm{H}$ ratios ranging from $1 \times 10^{-10}$ to $1 \times 10^{-13}$ have been measured from milligram sized samples. With improvements in system operation and sample preparation methodology, the sensitivity limit of the system is expected to increase to approximately $1 \times 10^{-15}$.

We believe that this prototype ${ }^{3} \mathrm{H}$ AMS system demonstrates the availability of a compact, sensitive, and cost effective instrument (anticipated commercial cost of approximately $\$ 750,000)$ to perform accurate measurement of ${ }^{3} \mathrm{H}$ from small samples. The capability of this system has the potential to significantly increase the application of ${ }^{3} \mathrm{H}$ AMS in the biomedical science and environmental research communities. 


\section{Appendix A: Description and Brief History of RFQ's}

An RFQ linac is a radio frequency (rf) accelerating structure that can simultaneously accelerate, focus, and efficiently bunch a high current, low energy ion beam. It can be designed as a resonant circuit, or as a resonant cavity. In the resonant cavity, it is essentially a vane-loaded cylinder excited with $\mathrm{rf}$ power in a modified $\mathrm{TE}_{210}$ cavity mode. In this mode, the rf circulating currents produce an electric quadrupole field in the region between the vanes. The transverse components of this field (uniform in space and alternating in time) give rise to strong, alternating-gradient, electric focusing effects that can focus charged particle beams injected along the axis of the structure. By scalloping the vane-tip geometry, as seen in Figure 5, a longitudinal component is introduced into these rf electric fields along the axis. This vane-tip 'modulation' is varied in amplitude to provide the amount of axial field desired. The length of the modulations varies to accommodate the velocity of the ions being accelerated, with the distance between the peaks on a vane being given by the velocity of particles in those cells divided by the structure's rf frequency (v/f). The modulations can be introduced gradually along the structure in order to adiabatically capture a low energy continuous ion beam into the rf accelerating 'buckets' and at the same time focus and accelerate it. As a result of the fixed profile of these vane modulations, the velocity profile of the accelerated particles is also fixed for a constant operating frequency. If the accelerating voltage is insufficient to allow the particles to stay in the accelerating field in each 'cell', they cannot be accelerated and drift through the structure, with most particles being lost by collisions with the vanes or walls of the structure.
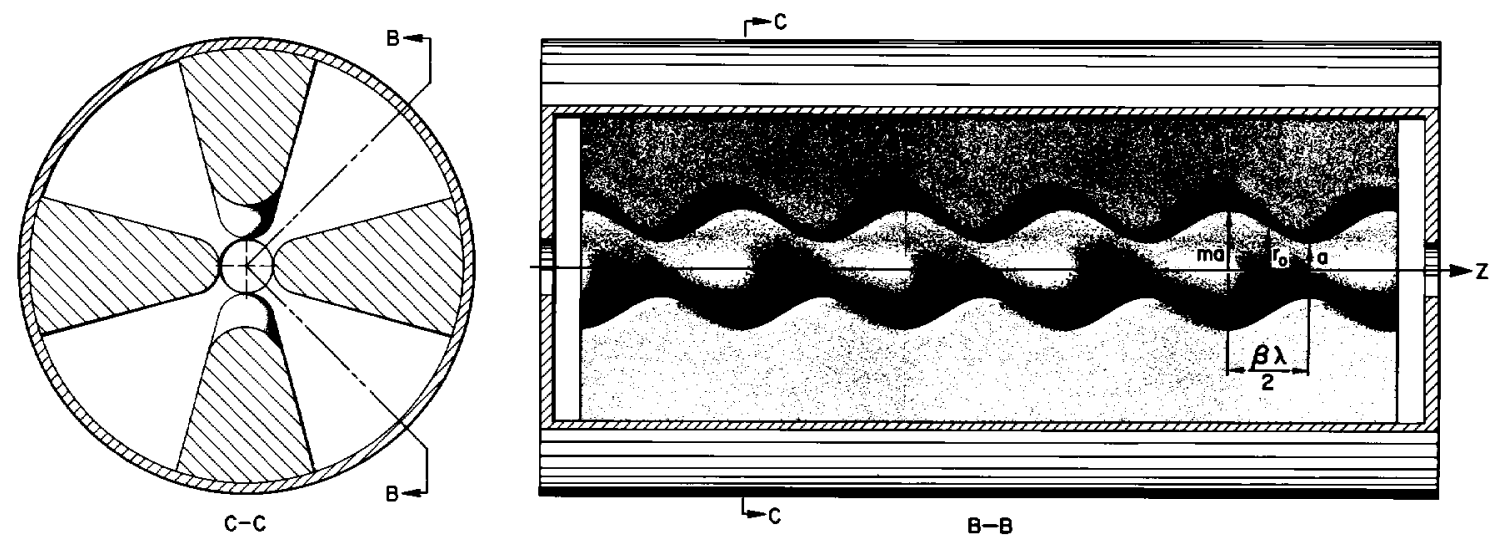

Figure 5. Schematic drawing of an RFQ structure. The cell length (v/2f) is expressed as the ratio of the particle velocity to the speed of light $(\beta=\mathrm{v} / \mathrm{c})$ multiplied by the free space wavelength $\lambda$. A cell is only $1 / 2$ of the vane tip modulation.

The RFQ concept was originally proposed in the Soviet Union in 1970 by Kapichinskii and Teplyakov ${ }^{[10]}$, but the technology was first developed and demonstrated in the United States at the Los Alamos National Laboratory (LANL). The first prototype was operated successfully at LANL in $1980^{[11]}$, and RFQ systems have been installed at more than fifty sites worldwide since then. The first commercial RFQ system was completed by AccSys Technology, Inc. as the injector for the proton therapy synchrotron at the Loma Linda University Medical Center in Southern California in $1989^{[12]}$, and commercial systems are now available from several companies worldwide. 


\section{References}

[1] J.S. Vogel and K.W. Turteltaub, 'Bimolecular Tracing through Accelerator Mass Spectrometry,' Trends in Analytical Chemistry, 11 (1992) 142-149.

[2] K.H. Dingley, S.P.H.T Freeman, D.O. Nelson, R.C. Garner, and K.W. Turteltaub, 'Covalent Binding of 2amino-3,8-dimethylimidazo[4,5-f]quinoxaline to Albumin and Hemoglobin at Environmentally-Relevant Doses: A Comparison of Humans and the F344 rat', Drug Metabolism and Disposition, 26 (1998) 825-828.

[3] K.W. Turteltaub and K.H. Dingley, 'Application of Accelerator Mass Spectrometry (AMS) in DNA Adduct Quantification and Identification,' Toxicology Letters, 102-103 (1998) 435-439.

[4] K.H. Dingley, K.D. Curtis, S. Nowell, J.S. Felton, N.P. Lang, and K.W. Turteltaub, 'DNA and Protein Adduct Formation in the Colon and Blood of Humans after Exposure to a Dietary-Relevant Dose of 2-amino-1-methyl6-phenylimidazo[4,5-b]pyridine,' Cancer Epidemiology, Biomarkers and Prevention, 8 (1999) 507-512.

[5] K.H. Dingley, M.L. Roberts, C. Velsko, and K.W. Turteltaub, 'Attomole detection of ${ }^{3}$ H in biological Samples Using Accelerator Mass Spectrometry: Application in Low-Dose, Dual-Isotope Tracer Studies in Conjunction

with ${ }^{14}$ C Accelerator Mass Spectrometry,' Chemical Research in Toxicology, Volume 11, No. 10, (1998) 1217-1222.

[6] J.R. Southon and M.L. Roberts, 'Ten Years of Sourcery at CAMS/LLNL - Evolution of a Cs Ion Source,' These proceedings.

[7] M.L. Roberts, P.J. Norman, J.L. Garibaldi, and R.S. Hornady, 'The New LLNL AMS Sample Changer,' Nuclear Instruments and Methods in Physics Research B92 (1994) 111-114.

[8] K. R. Crandall et. al., 'RFQ Design Codes,' Los Alamos Report Number LA-UR-96-1836 (Rev. 8/21/98).

[9] M.L. Roberts, C. Velsko, and K.W. Turteltaub, 'Tritium AMS for Biomedical Applications,' Nuclear Instruments and Methods in Physics Research B92 (1994) 459-462.

[10] I.M. Kapchinskii and V.A. Teplyakov, 'Linear Ion Accelerator with Spatially Homogeneous Strong Focusing,' Pub. Tekh. Eksp., No. 2, 19 (1970).

[11] J.E. Stovall, K.R. Crandall, and R.W. Hamm, 'Performance Characteristics of a 425 MHz RFQ Linac,' IEEE Trans. Nucl. Sci., NS-28, No. 2, 1501 (1981).

[12] J.M. Slater, 'Applying Charged Particle Physics Technology for Cancer Control at Loma Linda University Medical Center, USA,' 1990 European Particle Accelerator Conf., Nice, France, 286, Editions Frontieres (1990). 